\title{
Article \\ Effects and Mechanisms of Rhus chinensis Mill. Fruits on Suppressing RANKL-Induced Osteoclastogenesis by Network Pharmacology and Validation in RAW264.7 Cells
}

\author{
Yue Zheng ${ }^{1} \mathbb{D}$, Lei Zhao ${ }^{2}$, Junjie $\mathrm{Yi}^{1}{ }^{1}$ and Shengbao Cai ${ }^{1, *}$ \\ 1 Faculty of Food Science and Engineering, Kunming University of Science and Technology, \\ Kunming 650500, China; zheng_yue21@163.com (Y.Z.); junjieyi@kust.edu.cn (J.Y.) \\ 2 Beijing Engineering and Technology Research Center of Food Additives, \\ Beijing Technology and Business University, Beijing 100048, China; zhaolei@th.btbu.edu.cn \\ * Correspondence: caikmust2013@kmust.edu.cn; Tel.: +86-180-8755-5458
}

Citation: Zheng, Y.; Zhao, L.; Yi, J.; Cai, S. Effects and Mechanisms of Rhus chinensis Mill. Fruits on Suppressing RANKL-Induced Osteoclastogenesis by Network Pharmacology and Validation in RAW264.7 Cells. Nutrients 2022, 14 , 1020. https://doi.org/10.3390/ nu14051020

Academic Editor: Emad Al-Dujaili

Received: 24 January 2022

Accepted: 24 February 2022

Published: 28 February 2022

Publisher's Note: MDPI stays neutral with regard to jurisdictional claims in published maps and institutional affiliations.

Copyright: (ㅇ 2022 by the authors. Licensee MDPI, Basel, Switzerland. This article is an open access article distributed under the terms and conditions of the Creative Commons Attribution (CC BY) license (https:// creativecommons.org/licenses/by/ $4.0 /)$.

\begin{abstract}
Rhus chinensis Mill. fruits are a kind of widely distributed edible seasoning, which have been documented to possess a variety of biological activities. However, its inhibitory effect on osteoclast formation has not been determined. The objective of this study was to evaluate the effect of the fruits on osteoclast differentiation of RAW264.7 cells, induced by receptor activator of nuclear factor- $\mathrm{kB}$ ligand (RANKL) and to illuminate the potential mechanisms using network pharmacology and western blots. Results showed that the extract containing two organic acids and twelve phenolic substances could effectively inhibit osteoclast differentiation in RANKL-induced RAW264.7 cells. Network pharmacology examination and western blot investigation showed that the concentrate essentially decreased the expression levels of osteoclast-specific proteins, chiefly through nuclear factor kappa-B, protein kinase $B$, and mitogen-activated protein kinase signaling pathways, particularly protein kinase $B \alpha$ and mitogen-activated protein kinase 1 targets. Moreover, the extract likewise directly down regulated the expression of cellular oncogene Fos and nuclear factor of activated T-cells cytoplasmic 1 proteins. Citric acid, quercetin, myricetin-3-O-galactoside, and quercetin-3-O-rhamnoside were considered as the predominant bioactive ingredients. Results of this work may provide a scientific basis for the development and utilization of $R$. chinensis fruits as a natural edible material to prevent and/or alleviate osteoporosis-related diseases.
\end{abstract}

Keywords: Chinese sumac; osteoclast; osteoporosis; network pharmacology; phenolic compounds

\section{Introduction}

Human bones are constantly modified, and the dynamic balance of osteoblasts and osteoclasts is an important factor to maintain human bone health [1]. However, when this homeostasis becomes imbalanced, it can induce the growth of bone-solubilizing diseases, such as osteoporosis (OP) [2,3], osteosclerosis [4], etc. The main manifestations of OP are exacerbation of bone organization microarchitecture, reduction of bone density and an increase in susceptibility to fragile fractures [5]. OP can be mainly divided into primary OP and secondary OP, and the underlying pathogenesis is that bone loss is faster than bone formation [6-8]. With the development of medical technology and the standard of living, the average life expectancy of people is increasing which is accelerating the aging of society, resulting in a higher prevalence of OP [9]. The excessive activation of osteoclasts assumes a critical part in the pathology of OP [10]. Therefore, the inhibition of osteoclast differentiation has been considered as a potential therapy for the treatment and/or prevention of OP with few side effects.

Osteoclasts are a kind of novel multinucleated cell with bone resorbing capacity that originates from the bone marrow monocyte-macrophage lineage [11]. A major cascade 
of signals regulating osteoclast maturation and activation is the receptor activator of nuclear factor- $\mathrm{KB}$ (RANK) / receptor activator of nuclear factor- $\mathrm{kB}$ ligand (RANKL) pathway. RANKL facilitates osteoclast activation by combination with RANK on the cell membrane of osteoclast lineage cells [12]. After activation, the expression of many key transcription activators and enzymes increases, which in turn promote transdifferentiation, multiplication, and multi-nucleation of the osteoclast [4]. RANKL recruits tumor necrosis factor receptor-associated factor 6 (TRAF6) to activate a series of downstream cascades, including NF- $\mathrm{kB}, \mathrm{Akt}$, and MAPKs signaling pathways, and then further activates nuclear factor of activated T-cells cytoplasmic 1 (NFATc1) and cellular oncogene Fos (c-Fos), which are the final step for osteoclast formation [13]. Currently, the representative drugs for OP treatment are bisphosphonates and estrogens [14], but these substances inevitably cause varying degrees of side effects and complications in humans, such as osteonecrosis of the jaw and unrepresentative femur fractures [15]. Therefore, it is essential to develop some alternative dietary therapy with fewer side effects to prevent and/or improve OP.

Polyphenols are abundant in common edible fruits, vegetables and herbs. They have good antioxidant and anti-inflammatory activities and can maintain the health of the body [16]. At present, many studies have found that plant polyphenols have inhibitory effects on the formation of osteoclasts $[17,18]$. The study by Thomas et al. [17] showed that TRAP activity, an indicator of osteoclast differentiation, exhibited a downward trend with treatment using tart cherry polyphenols; moreover, result also showed that high doses of tart cherry polyphenols $(300 \mu \mathrm{g} / \mathrm{mL})$ could reduce the production of inflammatory markers, including nitric oxide content, cyclooxygenase 2, in RANKL-induced RAW264.7 cells, thereby reducing the differentiation and resorption activity of osteoclasts. Aronia melanocarpa 'Viking' (AM) was rich in phenolic compounds, and the study of Ghosh et al. [18], showed that the water and alcohol extracts of AM could inhibit the excessive accumulation of ROS, and the expression of osteoclast-related genes, including integrin $\beta_{3}$, TRAP, cathepsin K and calcitonin receptor; in addition, both extracts inhibited osteoclastogenesis by acting on the MAPKs pathway and blocking the signaling of c-Fos and NFATc1. Rhus chinensis pertains to the genus Rhus of the Anacardiaceae family, and is extensively distributed in Asia, including China, and Japan [19]. The fruits are commonly used as a kind of appetizer, beverage or natural vinegar by local people [19]. In addition, the fruits are recorded as a traditional herb with a wide range of bioactivities, which can be used to preclude and/or cure some diseases such as jaundice, alcoholism, hepatitis, and inflammatory diseases $[20,21]$. Rhus chinensis Mill. fruits have high nutritional value and are rich in a variety of polyphenols, polyunsaturated fatty acids and other phytochemicals [19]. For example, quercetin, myricetin-3-O-galactoside, and quercetin-3-O-rhamnoside are polyphenols that are abundant in $R$. chinensis fruits $[21,22]$. Some studies have reported that quercetin has related activities such as inhibiting osteoclastogenesis [23,24]. Kim et al. [23], found that quercetin could play an immunomodulatory role in interleukin-17 (IL-17) produced osteoclastogenesis. The results of Guo et al. [24], showed that quercetin could inhibit lipopolysaccharide-induced osteoclast bone resorption. Based on the above related findings, we speculated that $R$. chinensis fruits may have a bioactivity that inhibits the differentiation and formation of osteoclasts. However, no study has been carried out to investigate the preventive effects and the underlying mechanisms involved in the differentiation and formation of osteoclasts. The aim of this work was to investigate the preventive effects and potential mechanisms of the ethanolic extract from $R$. chinensis fruits against the differentiation and formation of osteoclasts by using network pharmacology and validation of results using cellular experiments (Figure 1). 


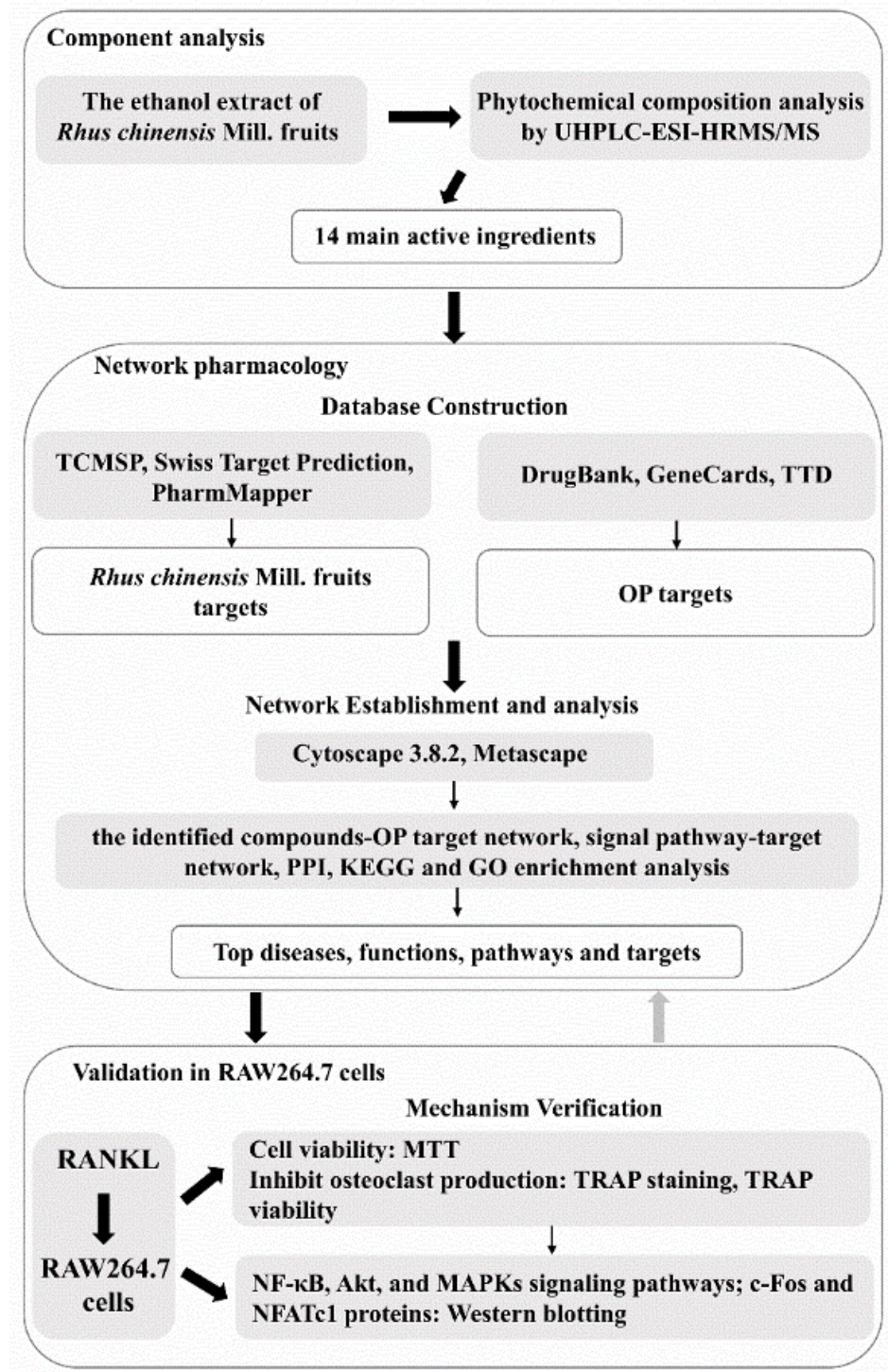

Figure 1. Workflow of the research. OP, osteoporosis; MTT, 3(4,5-Dimethylthiazol-2-yl)-2,5diphenyltetrazolium bromide; TRAP, tartrate-resistant acid phosphatase; RANKL, nuclear factor- $\mathrm{KB}$ ligand; NF-kB, nuclear factor kappa-B; c-Fos, cellular oncogene Fos; NFATc1, nuclear factor of activated T-cells cytoplasmic 1 .

\section{Materials and Methods}

\subsection{Reagents and Chemicals}

RANKL was obtained from R\&D Systems (Minneapolis, MN, USA). BCA protein assay kit, 3(4,5-Dimethylthiazol-2-yl)-2,5-diphenyltetrazolium bromide (MTT) and tartrateresistant acid phosphatase (TRAP) activity kits were supplied by Beyotime Biotechnology (Shanghai, China). Penicillin, streptomycin, Dulbecco's modified Eagle's medium (DMEM) and fetal bovine serum (FBS) were purchased from Gibco-Invitrogen (Karlsruhe, BadenWürttemberg, Germany). Cell lysis buffer with inhibitors of protease and phosphatase were provided by Nanjing Jiancheng Bioengineering Institute (Nanjing, China). Antibodies used in the current work, including NF- $\mathrm{B}, \mathrm{p}-\mathrm{I} \kappa \mathrm{B} \alpha, \mathrm{I} \kappa \mathrm{B} \alpha$, p-JNK (phospho-JNK1-T183/Y185 + JNK2-T183/Y185 + JNK3-T221/Y223), JNK, p-ERK (phospho-ERK1-T202/Y204 + ERK2T185/Y187), ERK, p38, p-p38 (phospho-p38 MAPK-T180/Y182 Rabbit pAb), Akt, p-Akt (Ser 473) and $\beta$-Actin were supplied by Wuhan Abclonal, China, and p-NF-kB, c-Fos, and NFATc1 were obtained from Affinity (Carlsbad, CA, USA). 


\subsection{Sample Preparation}

R. chinensis fruits were collected by Kunming Plant Classification Biotechnology Co. Ltd. (Kunming, China) from Tengchong County, Yunnan Province, in November 2019. All fruit materials were washed with tap water to remove impurities, dried naturally, and stored at $-20{ }^{\circ} \mathrm{C}$. The fruit was then freeze-dried, crushed to pass through a 40 mesh sieve. The $80 \%$ ethanolic extract was prepared in accordance with a former report [22] and the extract concentrated by a Heidolph Hei-VAP rotary evaporator (Hei-VAP Advantage, Heidolph, Germany) and freeze-dried.

\subsection{Characterization of Phytochemical Composition with UHPLC-ESI-HRMS/MS}

Phytochemical components in the extract were characterized by using the Ultimate 3000 UHPLC System of Thermo Fisher coupled with a Thermo Fisher Scientific Q-Exactive Orbitrap mass (Bremen, Germany). Phytochemical substances of the ethanolic extract from the fruits were first separated with a Zorbax SB-C18 column (Agilent, $2.1 \times 100 \mathrm{~mm}, 1.7 \mu \mathrm{m}$ ). The injection volume and flow rate were $3 \mu \mathrm{L}$ and $0.2 \mathrm{~mL} / \mathrm{min}$. The column temperature was set at $35^{\circ} \mathrm{C}$. Ultrapure water acidified by $0.1 \%$ formic acid (phase A) and acetonitrile (phase B) were applied as mobile phases. The following program was used as gradient elution conditions: $0-2 \mathrm{~min}, 5 \% \mathrm{~B} ; 2-10 \mathrm{~min}, 5-15 \% \mathrm{~B} ; 10-25 \mathrm{~min}, 15-30 \% \mathrm{~B}$; 25-30 $\mathrm{min}$, $30-50 \% \mathrm{~B} ; 30-32 \mathrm{~min}, 50-5 \% \mathrm{~B}$. The mass spectrum conditions were set according to our previous study [25]. The compounds were preliminarily or positively characterized by comparing the mass data of the compounds with the data in the corresponding standards, databases (mass bank) or references. Identified compounds were (semi-) quantified in accordance with the curved line of corresponding standards (or at least similar aglycones).

\subsection{Network Pharmacology Analysis}

For revealing the many potential substances in $R$. chinensis fruits against OP and their mechanism in inhibiting osteoclast differentiation, network pharmacology was applied in the present work. First, the standard structures of the detected components in R. chinensis fruits were obtained from PubChem (https://pubchem.ncbi.nlm.nih.gov, accessed on 28 July 2021). Then the Traditional Chinese Medicine Systems Pharmacology Database (TCMSP, http: / / tcmspw.com/tcmsp.php, accessed on 28 July 2021) [26], Swiss Target Prediction (http: / / www.swisstargetprediction.cn, accessed on 28 July 2021) [27] and PharmMapper (http: / / www.lilab-ecust.cn/pharmmapper/, accessed on 28 July 2021) [28] were applied to search and screen the related targets of the bioactive substances. Keyword "osteoporosis", was used in DrugBank (https:/ / go.drugbank.com, accessed on 28 July 2021) [29], GeneCards (https: / / genecards.weizmann.ac.il/v3/, accessed on 28 July 2021) [30] and TherapeuticTargetDatabase (TTD, http:/ /db.idrblab.net/ttd/, accessed on 28 July 2021) [31] to gather disease targets. UniProtKB (https:/ / www.uniprot.org/, accessed on 29 July 2021) [32] was applied to obtain the name of the standard target with "Homo sapiens" as the selected organism. The Venn online platform (http:/ / bioinformatics.psb.ugent.be/webtools/Venn/, accessed on 29 July 2021) was applied to intersect the active ingredient targets and disease targets retrieved from the above mentioned database. Then, the common target of active ingredients and diseases were obtained, which was the target of prevention and treatment of osteoporosis by the ethanolic extract of $R$. chinensis. fruits. Cytoscape 3.8.2 software was applied to establish the active ingredient-target network, signal pathway-target network or protein-protein interaction (PPI) network. KEGG and GO enrichment analyses were performed by Metascape (https:/ / metascape.org/gp/index.html\#/main/step1, accessed on 30 July 2021). Histograms were plotted by http:/ / www.bioinformatics.com.cn (accessed on 30 July 2021).

\subsection{Cell Culture and Cytotoxicity Test}

RAW264.7 cells obtained from the Kunming cell bank of the Chinese Academy of Sciences (Kunming, China) were incubated in DMEM medium with $10 \%$ FBS. The culture temperature was $37^{\circ} \mathrm{C}$ and the $\mathrm{CO}_{2}$ concentration was $5 \%$. The MTT method was used to 
evaluate the cytotoxicity of the ethanolic extract at $50 \mu \mathrm{g} / \mathrm{mL}$ or $100 \mu \mathrm{g} / \mathrm{mL}$ with RAW264.7 cells as previously reported [25]. Results showed that both concentrations of the ethanolic extract exhibited no cellular toxicity to RAW264.7 cells.

\subsection{TRAP Staining}

RAW264.7 cells seeded in 96-well plates were set up in accordance with the above concentrations in the following groups: Group K (Control group), Group M (50 ng/mL RANKL), Group RL (50 ng/mL RANKL and $50 \mu \mathrm{g} / \mathrm{mL}$ of extract), and group RH (50 ng/mL RANKL and $100 \mu \mathrm{g} / \mathrm{mL}$ of extract). The solution was changed every other day. After incubation for 5 days, the cells were stained according to the instructions of the TRAP staining kit.

\subsection{TRAP Viability Examination}

RAW264.7 cells seeded into 6-well plates were cultured according to the above method. After being cultured for five days, TRAP activity of each well was detected according to the kit instructions for TRAP viability.

\subsection{Analysis by Western Blots}

RAW264.7 cells seeded into 6-well plates were cultured according to the above method. The solution was replaced every other day for five days. All cells were homogenized in cell lysis buffer with a scientz-IID ultrasonic cell crusher (Ningbo Scientz Biotech Co., Ltd., Ningbo, China). Western blot analyses were carried out according to the previously reported method [19].

\subsection{Statistical Analysis}

All data are expressed as average \pm standard deviation (S.D.). The data were evaluated with one-way ANOVA, and the significance $(p<0.05)$ was tested by Tukey's test. TRAP staining was performed by Media Cybernetics Inc. (Rockville, MD, USA) using the software image-Pro Plus 6.0. Origin 8.5 software was used for data analyses in the current work.

\section{Results}

\subsection{Phytochemical Composition Analysis}

The mass spectra in negative ion mode of the $80 \%$ ethanolic extract are shown in Figure 2. Related mass data (e.g., $m / z$, molecular formula, ion fragments) are presented in Table 1 for the identification of these substances. When comparing the mass data of the ethanolic extract to the mass data obtained from the literature, phytochemical standards or mass bank, 14 substances were identified, two of which were organic acids and 12 were phenols. Among those 12 phenolic compounds, five substances belonged to gallic acid and its derivatives (compounds 3-7) and the remaining seven compounds were flavonoids and its derivatives (compounds 8, 9, 10, 11, 12, 13 and 14). Table 1 summarizes the quantitative and semi-quantitative results of 14 phytochemical compounds. The malic acid $(144,519.79 \pm 21,651.25 \mu \mathrm{g} / \mathrm{g})$ and citric acid $(135,452.78 \pm 16,530.37 \mu \mathrm{g} / \mathrm{g})$ comprised the most content, both of which are organic acids. The phenolic compound with the highest content was gallic acid (3791.02 $\pm 490.83 \mu \mathrm{g} / \mathrm{g})$, followed by quercetin-3-O-rhamnoside (quercitrin, $3592.77 \pm 463.06 \mu \mathrm{g} / \mathrm{g}$ ) and myricetin-3-O-rhamnoside $(525.43 \pm 64.31 \mu \mathrm{g} / \mathrm{g})$, indicating that those three substances were the principal phenolic compounds of the ethanolic extract of $R$. chinensis fruits. 


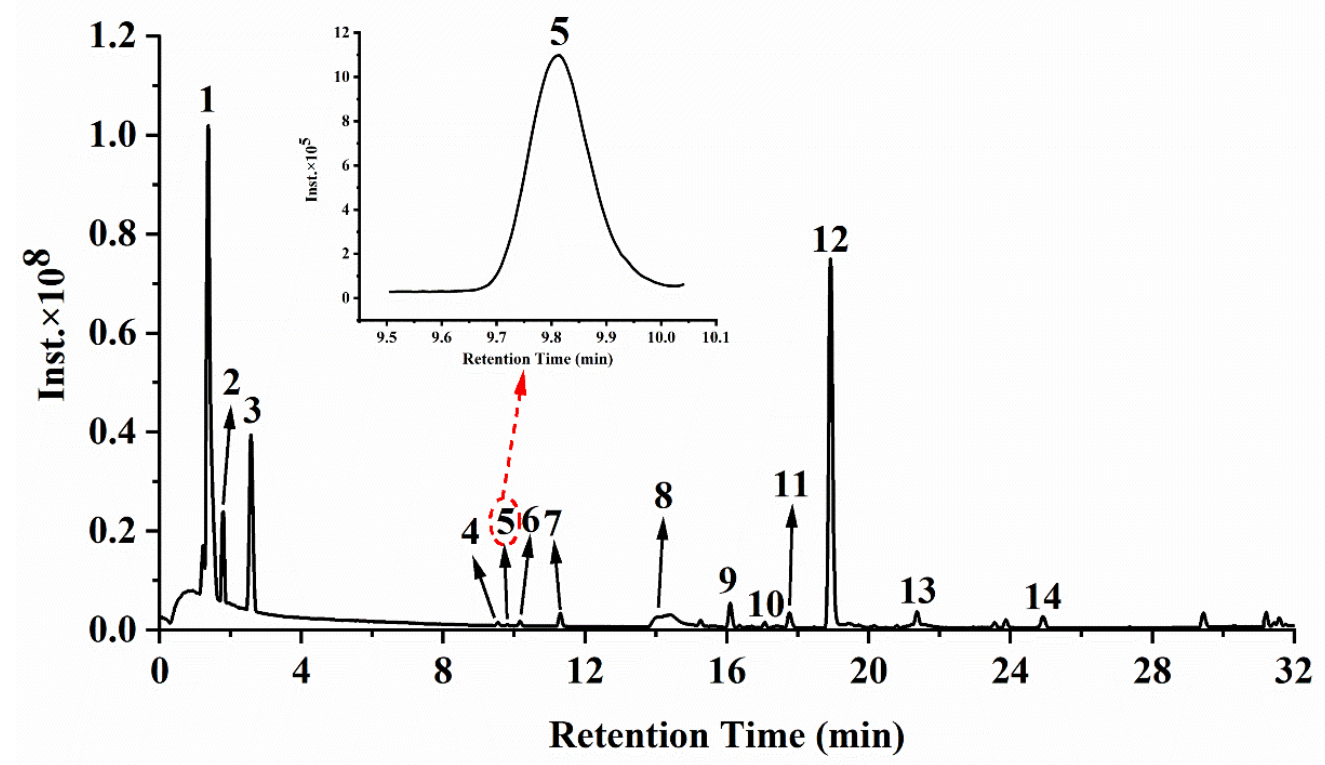

Figure 2. Mass chromatograms of the ethanolic extract from $R$. chinensis fruits in negative mode. Peaks 1-14 refer to the corresponding compounds in Table 1.

\subsection{Network Pharmacology Analysis}

A total of 354 potential targets of the identified substances in the ethanolic extract $R$. chinensis fruits were predicted by using TCMSP, Swiss Target Prediction, and PharmMapper databases. After searching from DrugBank, GeneCards, and TTD databases, 1299 targets related to $\mathrm{OP}$ were identified. By comparing potential targets of the identified substances with OP-related targets, 94 intersection targets were determined as the possible targets of the ethanolic extract towards OP (Figure 3a). A compound-target network was established to identify the correlation between the identified compounds and their potential targets (Figure 3b). Citric acid, quercetin, myricetin-3-O-galactoside and quercetin-3-O-rhamnoside were the four compounds most associated with OP-related targets $(44,39,33$ and $33 \mathrm{OP}$ related targets, respectively). Meanwhile, citric acid and quercetin-3-O-rhamnoside were the predominant phytochemicals in the extract (Figure 2 and Table 1). However, malic acid and gallic acid were also the most abundant compounds contained in the extract, but these two substances were associated with fewer OP-related targets (5 and 10 OP-related targets, respectively). 
Table 1. Chemical composition identified in R. chinensis Mill. fruits by UHPLC-ESI-HRMS/MS.

\begin{tabular}{|c|c|c|c|c|c|c|c|}
\hline $\begin{array}{c}\text { Peak } \\
\text { No. }\end{array}$ & $\begin{array}{c}\text { RT } \\
\text { (Min) }\end{array}$ & Compounds & $\begin{array}{c}{[\mathbf{M}-\mathbf{H}]^{-}} \\
\quad(\mathrm{m} / \mathrm{z})\end{array}$ & $\begin{array}{l}\text { Molecular } \\
\text { Formula }\end{array}$ & MS/MS Fragment Ions & Dry Extract $(\mu \mathrm{g} / g)$ & Reference \\
\hline 1 & 1.37 & Malic acid & 133.0130 & $\mathrm{C}_{4} \mathrm{H}_{6} \mathrm{O}_{5}$ & $115.1210(100)$ & $144,519.80 \pm 21,651.25$ & Standard \\
\hline 2 & 1.80 & Citric acid & 191.0189 & $\mathrm{C}_{6} \mathrm{H}_{8} \mathrm{O}_{7}$ & 87.0075(100), 57.0332(91), 111.0075(48) & $135,452.78 \pm 16,530.37$ & Standard \\
\hline 3 & 2.58 & Gallic acid & 169.0133 & $\mathrm{C}_{7} \mathrm{H}_{6} \mathrm{O}_{5}$ & 69.0331(100), 124.0152(55), $125.0232(33)$ & $3791.02 \pm 490.83$ & Standard \\
\hline 4 & 9.55 & Digallic acid & 321.0252 & $\mathrm{C}_{14} \mathrm{H}_{10} \mathrm{O}_{9}$ & $125.0232(100), 169.0133(23)$ & $148.89 \pm 20.36$ & [33] \\
\hline 5 & 9.81 & Trigalloyl glucose isomer I & 635.0894 & $\mathrm{C}_{27} \mathrm{H}_{24} \mathrm{O}_{18}$ & 169.0134(100), 483.0779(16), 635.0867(2) & $108.30 \pm 13.08$ & [34] \\
\hline 6 & 10.17 & Trigalloyl glucose isomer II & 635.0895 & $\mathrm{C}_{27} \mathrm{H}_{24} \mathrm{O}_{18}$ & 169.0133(100), 483.0778(9), 635.0895(4) & $167.08 \pm 22.72$ & [34] \\
\hline 7 & 11.30 & Trigalloyl glucose isomer III & 635.0893 & $\mathrm{C}_{27} \mathrm{H}_{24} \mathrm{O}_{18}$ & 169.0134(100), 483.0783(15), 635.0930(4) & $326.75 \pm 40.48$ & [34] \\
\hline 8 & 14.11 & Myricetin-3-O-galactoside & 479.0838 & $\mathrm{C}_{21} \mathrm{H}_{20} \mathrm{O}_{13}$ & $316.0224(100), 317.0271(26)$ & $61.27 \pm 6.97$ & Mass bank \\
\hline 9 & 16.10 & Myricetin-3-O-rhamnoside & 463.0886 & $\mathrm{C}_{21} \mathrm{H}_{20} \mathrm{O}_{12}$ & $316.0225(100), 317.0276(24)$ & $525.43 \pm 64.31$ & Standard \\
\hline 10 & 17.07 & Luteolin-7-O-glucoside & 447.0933 & $\mathrm{C}_{21} \mathrm{H}_{20} \mathrm{O}_{11}$ & $285.0402(100), 284.0327(53)$ & $81.57 \pm 10.60$ & Standard \\
\hline 11 & 17.90 & Quercetin-3-O-arabinoside & 433.0775 & $\mathrm{C}_{20} \mathrm{H}_{18} \mathrm{O}_{11}$ & $300.0275(100), 301.0331(17)$ & $50.69 \pm 7.59$ & [33] \\
\hline 12 & 18.92 & Quercetin-3-O-rhamnoside & 447.0931 & $\mathrm{C}_{21} \mathrm{H}_{20} \mathrm{O}_{11}$ & $300.0276(100), 301.0341(54), 151.0029(23)$ & $3592.77 \pm 463.06$ & Standard \\
\hline 13 & 21.37 & Kaempferol-3-O-hexoside & 431.0984 & $\mathrm{C}_{21} \mathrm{H}_{22} \mathrm{O}_{10}$ & $284.0326(96), 285.0397(68)$ & $177.93 \pm 21.13$ & [34] \\
\hline 14 & 24.91 & Quercetin & 301.0354 & $\mathrm{C}_{15} \mathrm{H}_{10} \mathrm{O}_{7}$ & $151.0026(100)$ & $173.38 \pm 24.54$ & Standard \\
\hline
\end{tabular}

RT: retention time; the results were expressed as $\mu \mathrm{g} / \mathrm{g}$ of dry extract. All the values are expressed as mean $\pm \mathrm{SD}(n=3)$. Malic acid standard was used for quantifying compounds $1 ;$ Citric acid standard was used for quantifying compounds 2; gallic acid standard was used for quantifying compounds 3, 4, 5, 6, 7; myricetin-3-O-rhamnoside standard was used for quantifying compounds 8, 9; luteolin-7-O-glucoside standard was used for quantifying compound 10; quercetin-3-O-rhamnoside standard was used for quantifying compounds 11 and 12; kaempferol standard was used for quantifying compound 13; quercetin standard was used for quantifying compound 14. 


\section{a}
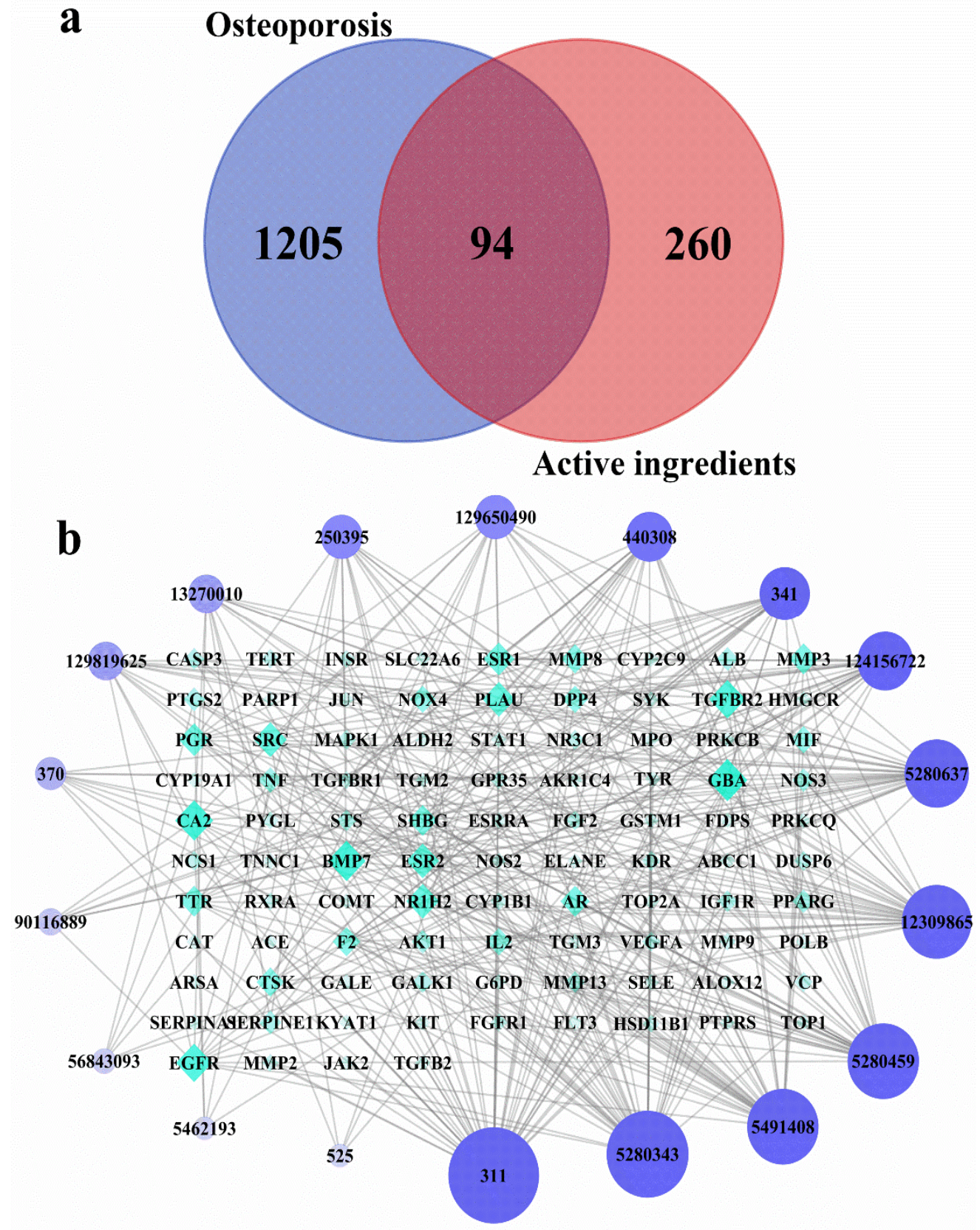

Figure 3. Screening of intersecting targets and construction of network diagrams of chemical components and targets. (a) A Venn diagram showing the intersections of identified targets of identified compounds and osteoporosis; (b) The identified compounds-osteoporosis target network. The color and size of each icon reflects the node degree for the common targets. The active ingredients include: Malic acid (525, Peak 1), Citric acid (311, Peak 2), Gallic acid (370, Peak 3), Digallic acid (341, Peak 4), 1,2,3-tri-O-galloyl-d-glucose (13270010, Peak 5 or 6 or 7), 1,2,6-trigalloyl-betad-glucose (124156722, Peak 5 or 6 or 7), 1,2,6-Trigalloyl-glucose (440308, Peak 5 or 6 or 7), 1,3,6tri-O-galloylglucose (250395, Peak 5 or 6 or 7), 1,4,6-Trigalloylglucose (129650490, Peak 5 or 6 or 7), 2,3,6-trigalloyl-d-glucose (129819625, Peak 5 or 6 or 7), Trigalloylglucose (90116889, Peak 5 or 6 or 7), Myricetin-3-O-galactoside (5491408, Peak 8), Myricetin-3-O-rhamnoside (56843093, Peak 9), Luteolin-7-O-glucoside (5280637, Peak 10), Quercetin-3-O-arabinoside (12309865, Peak 11), Quercetin3-O-rhamnoside (5280459, Peak 12), Kaempferol-3-O-hexoside (5462193, Peak 13), Quercetin (5280343, Peak 14). 
The 94 intersection targets were further analyzed by Bisogenet to construct a PPI network, and the results are shown in Figure 4. Altogether 77 important nodes were identified in the PPI network. The top 20 enriched GO terms in each category are shown in Figure 5. The screened targets mainly involved biological processes, including "proliferation of muscle cell (GO:0033002)", "regulation of proliferation of smooth muscle cell (GO:0048660)" and "proliferation of smooth muscle cell (GO:0048659)". While "vesicle lumen (GO:0031983)", "cytoplasmic vesicle lumen (GO:0060205)" and "secretory granule lumen (GO:0034774)" ranked the highest in the molecular function category, "activity of ligand-activated transcription factor (GO:0098531)", "nuclear receptor activity (GO:0004879)", and "activity of transmembrane receptor protein kinase (GO:0019199)" were the main cellular component categories. The crucial signaling pathways involved were further illuminated by enrichment analysis of KEGG pathway (Figure 6). The top three KEGG pathways (Figure 6a) were the PI3K-Akt (hsa04151), AGE-RAGE (hsa04933), and MAPKs (hsa04010) signaling pathways. In accordance with the number of targets found in each signaling pathway, Cytoscape (3.8.2) software was applied to establish a target-signal pathway network. The target-pathway network consisted of 60 nodes and 158 edges (Figure 6b). The results showed that Mitogen-activated protein kinase 1 (MAPK1) and RAC-alpha serine/threonine-protein kinase (AKT1) were the two most critical targets, which involved 14 and 13 pathways, respectively. Combined with PPI and enrichment analysis of KEGG pathways and the target-signaling pathway network, AKT1 and MAPK1 are relatively key targets. They are associated with more pathways (Figure $6 \mathrm{~b}$ ) and interact closely with other targets (Figure 4). Among all phytochemical components, quercetin-3-O-rhamnoside and quercetin-3-O-arabinoside inhibited both targets. Citric acid, quercetin, and 1,2,6-trigalloylbeta-d-glucose inhibited AKT1, while myricetin-3-O-galactoside inhibited MAPK1.

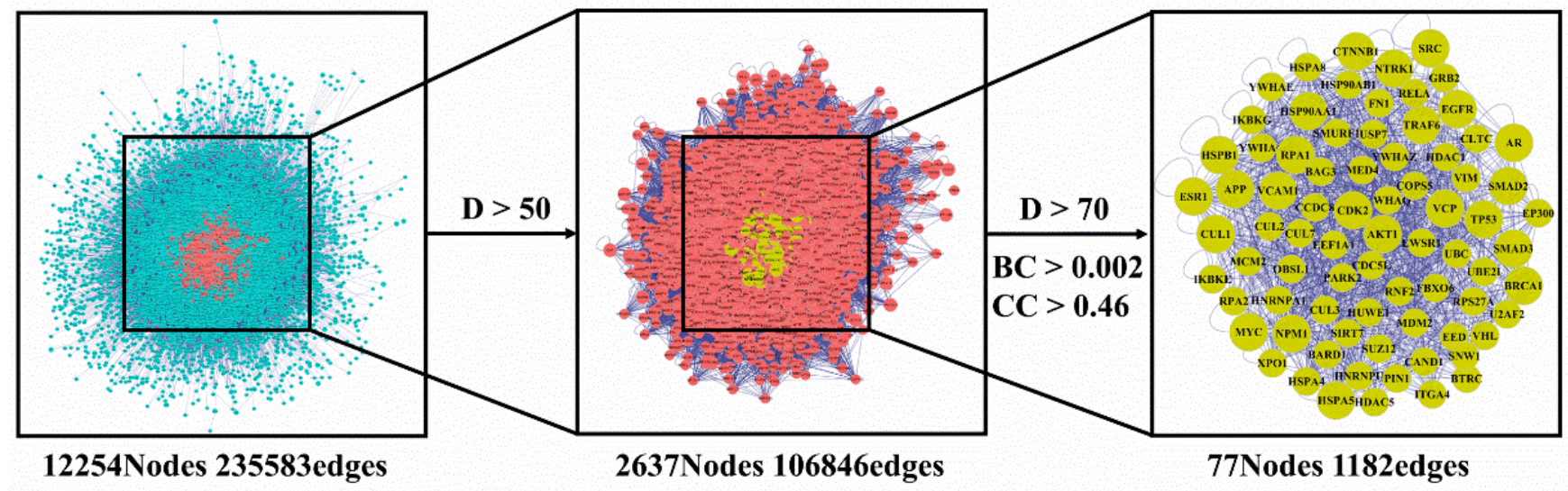

Figure 4. Common targets of compounds and osteoporosis PPI network. PPI, protein-protein interaction; D, Degree; BC, Betweenness Centrality; CC, Closeness Centrality.

\subsection{Inhibition of Osteoclast Differentiation}

After five days of RANKL induction, the cells were incubated with or without ethanolic extract and stained with a TRAP staining kit, and the relative area of TRAP-positive cells was quantified with image pro plus software. At the same time, a TRAP activity kit was used to determine the TRAP activity of cells. As shown in Figure 7a, RAW264.7 cells in the $\mathrm{M}$ group differentiated into a large number of TRAP-positive osteoclasts. After adding $50 \mu \mathrm{g} / \mathrm{mL}$ (the RL group) and $100 \mu \mathrm{g} / \mathrm{mL}$ (the RH group) ethanolic extracts, the formation of TRAP-positive osteoclasts was clearly inhibited. As shown in Figure 7b, when compared to the M group, the TRAP-positive osteoclasts in the RL and RH groups had evidently declined $(p<0.05)$, remarkably in the RH group, in which the TRAP-positive osteoclasts were similar to those in the K group $(p>0.05)$. It can be seen from the results of the TRAP activity (Figure 7c) that the TRAP activity of the M group increased when compared with that of the K group $(p<0.05)$, while the TRAP activities of the RL and RH groups were remarkably lower than the M group $(p<0.05)$, and no difference in TRAP 
activity between the RH and K groups was observed $(p>0.05)$, which were consistent with the staining results.

a

GO:0033002:muscle cell proliferationGO:0048660:regulation of smooth muscle cell proliferation GO:0048659:smooth muscle cell proliferationGO:0030335:positive regulation of cell migrationGO:0001934:positive regulation of protein phosphorylationGO:2000147:positive regulation of cell motility GO:0040017:positive regulation of locomotio GO:0051272:positive regulation of cellular component movementGO:0048545:response to steroid hormone GO:0043408:regulation of MAPK cascadeGO:0043549:regulation of kinase activity GO:0051347:positive regulation of transferase activityGO:0010035:response to inorganic substance GO:0032870:cellular response to hormone stimulus GO:0006979:response to oxidative stressGO:0062197:cellular response to chemical stress GO:0072593:reactive oxygen species metabolic process GO:0000165:MAPK cascade GO:0010942:positive regulation of cell death GO:0033674:positive regulation of kinase activity

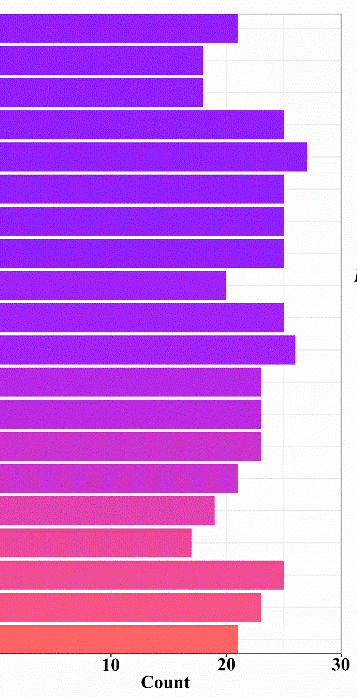
$p$ value $4.330000 \times 10^{-15}$ $3.247531 \times 10^{-15}$ $2.165062 \times 10^{-15}$ $1.082594 \times 10^{-15}$

b

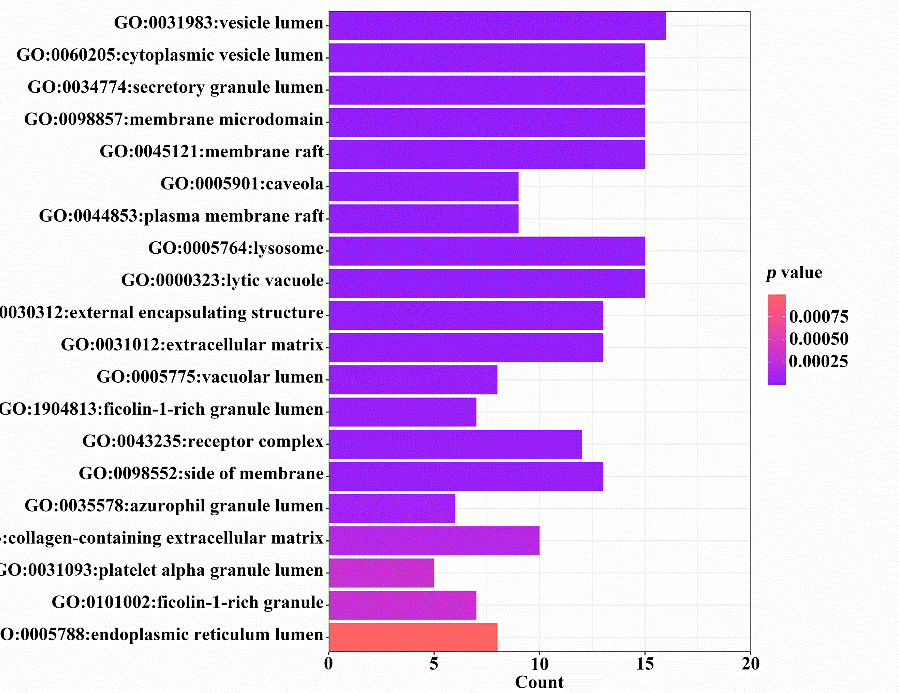

c

GO:0098531:ligand-activated transcription factor activity GO:0004879:nuclear receptor activity GO:0019199:transmembrane receptor protein kinase activity GO:0042803:protein homodimerization activity GO:0020037:heme binding GO:0046906:tetrapyrrole binding GO:0004672:protein kinase activity GO:0016773:phosphotransferase activity, alcohol group as acceptor GO:0004714:transmembrane receptor protein tyrosine kinase activity GO:0016301:kinase activity GO:0004713:protein tyrosine kinase activity GO:0008236:serine-type peptidase activity GO:0017171:serine hydrolase activity GO:0004252:serine-type endopeptidase activity GO:0019901:protein kinase binding GO:0016922:nuclear receptor binding GO:0005496:steroid binding GO:0005126:cytokine receptor binding GO:0016491:oxidoreductase activity GO:0019900:kinase binding

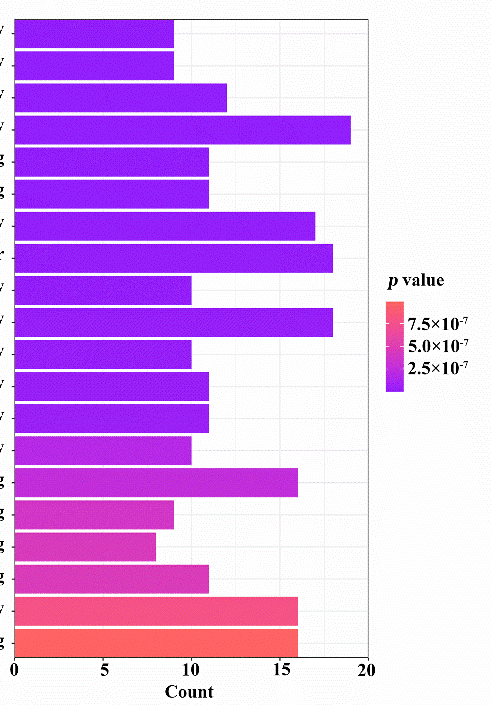

Figure 5. GO enrichment analysis of 94 common targets ( $p$-value < 0.05). (a) Top 20 significantly enriched GO terms in "biological process" (BP); (b) "cellular component" (CC); and (c) "molecular function" (MF) are shown. Enrichment scores represent-log $p$ values. 
a hsa04151:PI3K-Akt signaling pathway hsa04933:AGE-RAGE signaling pathway in diabetic complications hsa04010:MAPK signaling pathway hsa04014: Ras signaling pathway hsa04015:Rap1 signaling pathway hsa04915:Estrogen signaling pathway hsa04380:Osteoclast differentiation hsa04066:HIF-1 signaling pathway hsa04068:foxo signaling pathway hsa04668:TNF signaling pathway hsa04657:IL-17 signaling pathway hsa04370:VEGF signaling pathway hsa04919:thyroid hormone signaling pathway hsa04064:NF-kappa B signaling pathway hsa04917:Prolactin signaling pathway

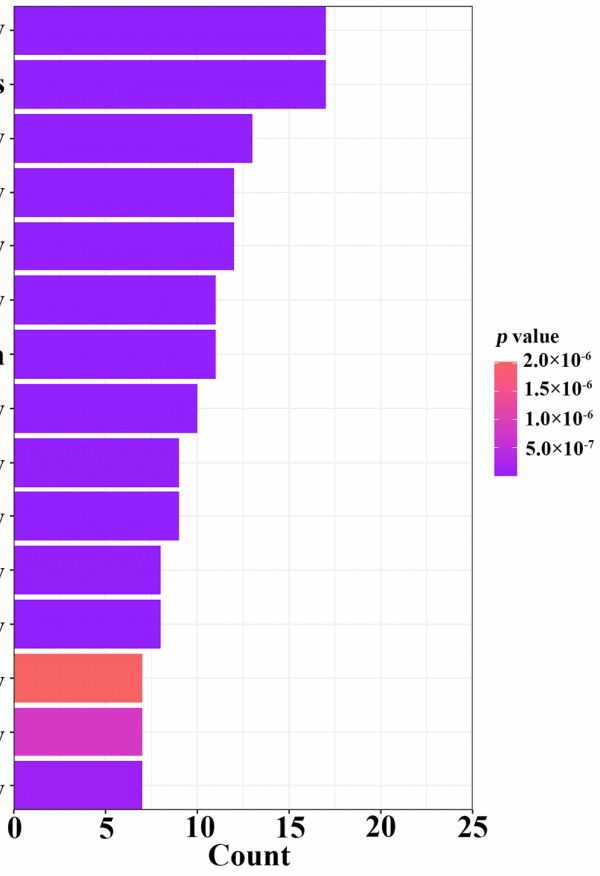

hsa04668:TNF

b

hsa04370:VEGF

hsa04068:foxo signaling pathway
hsa04066:HIF-1

signaling pathway hsa04915: Estrogen signaling pathway signaling pathway ${ }_{\text {STAT1 MMP2 TNNC1 EGFR PPARG MAPK1 hsa04380:Osteoclast }}$

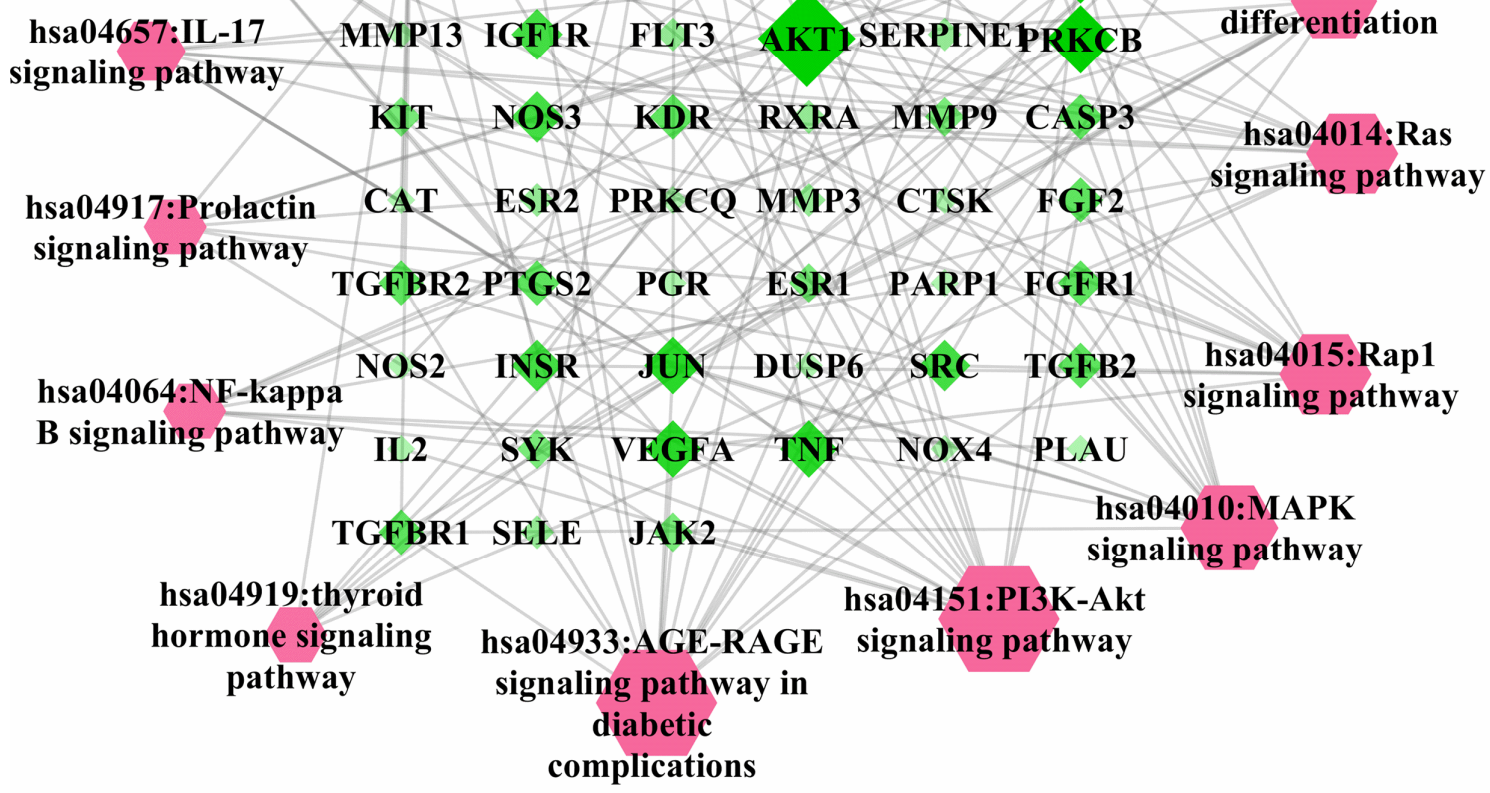

Figure 6. KEGG pathway enrichment analysis of 94 common targets ( $p$-value $<0.05$ ) and the genepathway network of the identified compounds against osteoporosis. (a) KEGG pathways; (b) Genepathway network. The color and size of each icon reflects the node degree for the common targets. 


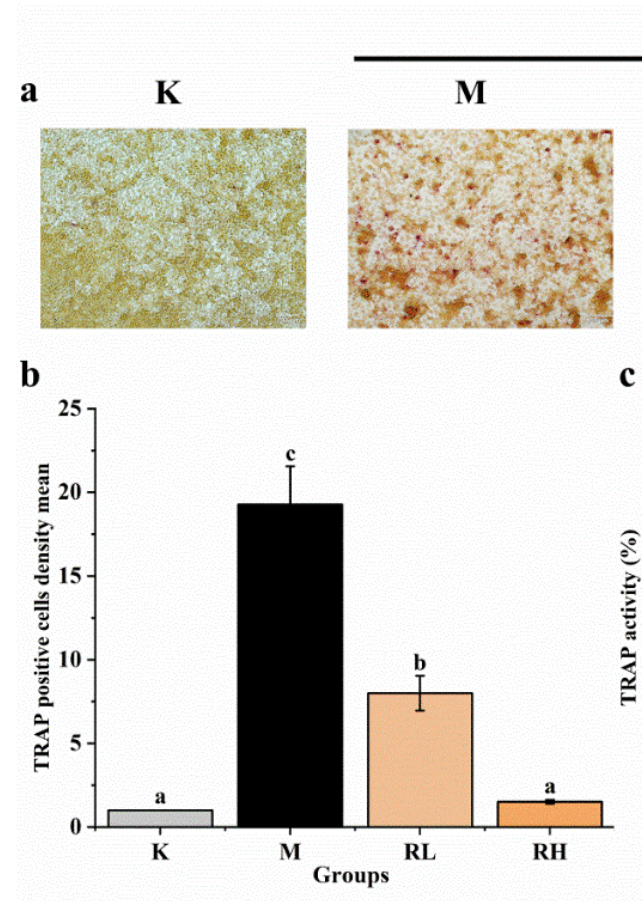

\section{RANKL}

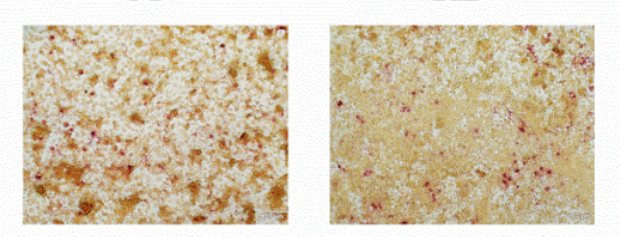

RH

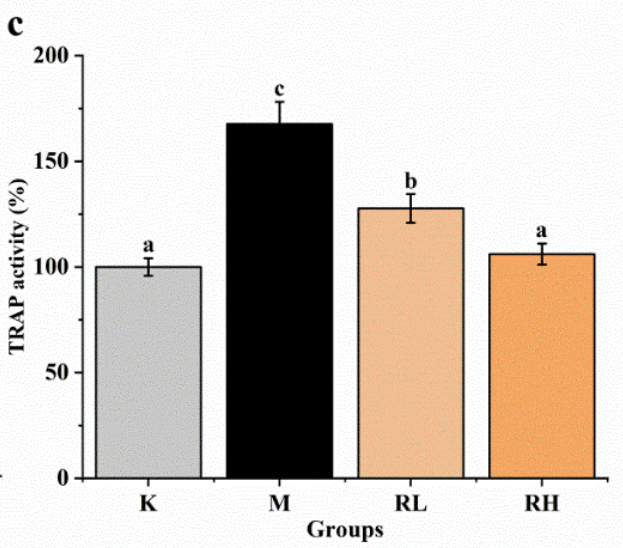

Figure 7. Effects of the ethanolic extract from R. chinensis fruits on RANKL-induced osteoclastogenesis in RAW264.7 cells. (a) TRAP staining; (b) Relative area of TRAP-positive signal, normalized with the K group; (c) Quantitative results of TRAP activity. All the values are expressed as mean \pm SD $(n=3)$. Groups with different letters are significantly different $(p<0.05)$. The TRAP positive cells after TRAP staining were quantified using Image-Pro Plus software. The quantitative result is expressed in terms of density mean (density mean = density sum/area sum) and the TRAP positive cells were quantified by normalizing with group K. K, the Control group; M, $50 \mathrm{ng} / \mathrm{mL}$ RANKL; RL, $50 \mathrm{ng} / \mathrm{mL}$ RANKL and $50 \mu \mathrm{g} / \mathrm{mL}$ of ethanolic extract; RH, $50 \mathrm{ng} / \mathrm{mL}$ RANKL and $100 \mu \mathrm{g} / \mathrm{mL}$ of ethanolic extract; TRAP, tartrate-resistant acid phosphatase; RANKL, receptor activator of nuclear factor- $\mathrm{kB}$ ligand.

\subsection{Ethanolic Extract Inhibits Osteoclastogenesis through MAPKs, NF- $\kappa B$ and Akt Signaling Pathways}

Western blot assays of several signaling pathways were used to further confirm the possible mechanisms of $R$. chinensis fruits on RANKL-induced osteoclastogenesis, and the results are presented in Figure 8. After induction by RANKL for 5 days, the levels of some key proteins (p-NF- $\mathrm{B}, \mathrm{NF}-\kappa \mathrm{B}, \mathrm{p}-\mathrm{I} \kappa \mathrm{B} \alpha, \mathrm{I} \kappa \mathrm{B} \alpha, \mathrm{p}-\mathrm{ERK}, \mathrm{ERK}, \mathrm{p}-\mathrm{JNK}, \mathrm{JNK}$ p-p38, p38, $\mathrm{p}-\mathrm{Akt}, \mathrm{Akt})$ in cells were determined. The expression of $\mathrm{p}-\mathrm{NF}-\kappa \mathrm{B} / \mathrm{NF}-\kappa \mathrm{B}, \mathrm{p}-\mathrm{I} \kappa \mathrm{B} \alpha / \mathrm{I} \kappa \mathrm{B} \alpha$, p-ERK/ERK, p-JNK/JNK, p-p38/p38 and p-Akt/Akt in the M group were significantly higher than their counterparts in the $\mathrm{K}$ group $(p<0.05)$. The expression of almost all proteins in the RL group and RH group were obviously less than that of the relevant protein in the $\mathrm{M}$ group $(p<0.05)$, except for $\mathrm{p}-\mathrm{p} 38 / \mathrm{p} 38$ in the RL group (Figure $8 \mathrm{~b}, \mathrm{~d}$ ).

\subsection{Inhibition of c-Fos and NFATc1 Expression by Ethanolic Extract}

As shown in Figure 9, the expressions of both c-Fos and NFATc1 in group M were significantly higher than that of the corresponding protein in Group $\mathrm{K}(p<0.05)$. However, the expression levels of c-Fos and NFATc1 (Figure 9b,c) in the RL group and RH group were significantly less when compared to the corresponding protein in the M group $(p<0.05)$. According to these results, we can calculate that the ethanolic extract of the fruits could efficiently suppress NFATc1 and c-Fos protein expression during the RANKL induction period, indicating that NFATc1 and c-Fos may also be one of its potential targets for inhibiting osteoclastogenesis. 

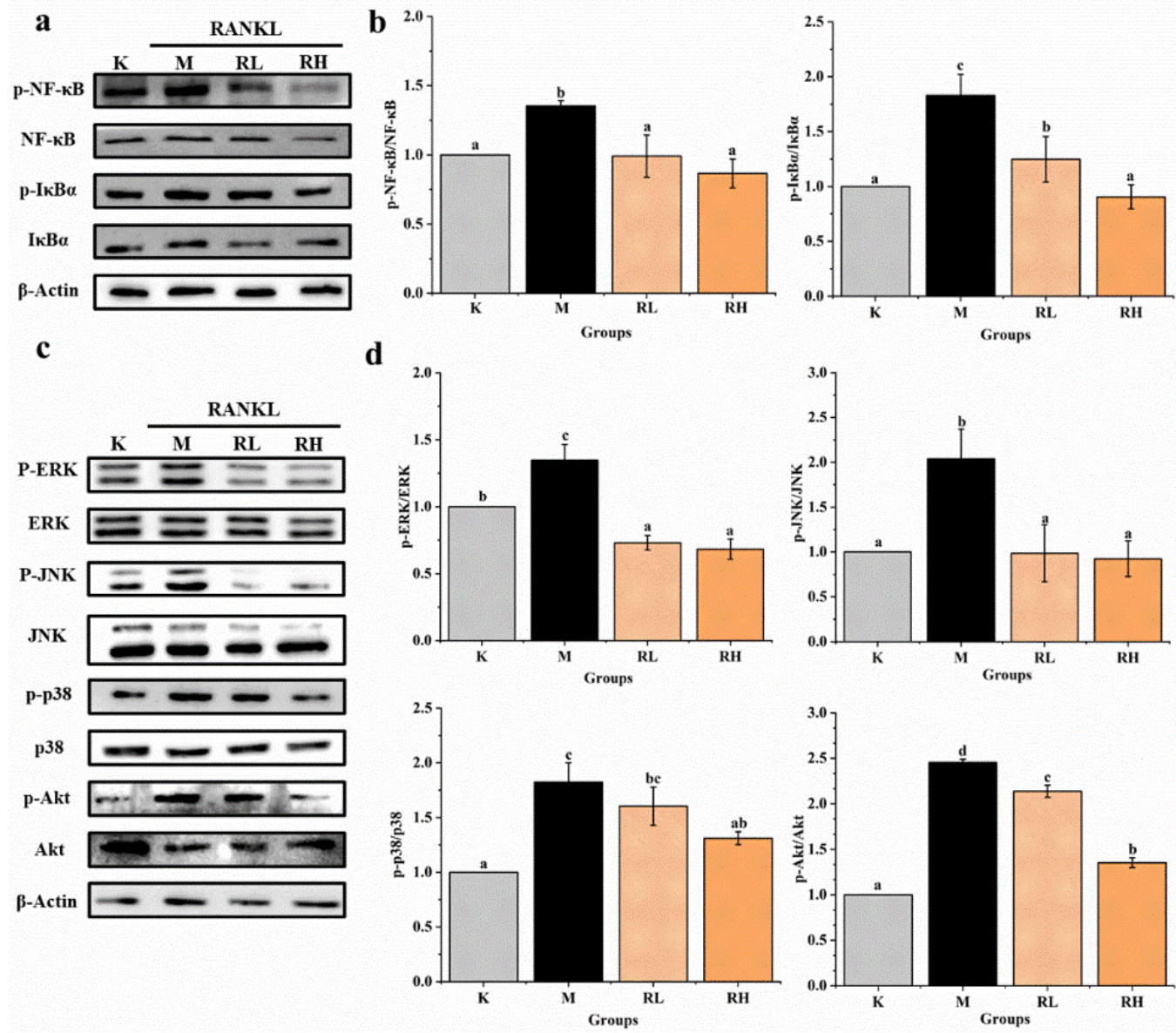

Figure 8. Effects of the ethanolic extract from R. chinensis fruits on RANKL-induced osteoclastogenesis to NF-kB, Akt, and MAPKs signaling pathways in RAW264.7 cells. (a) Western blot analysis of $\mathrm{p}-\mathrm{NF}-\kappa \mathrm{B} / \mathrm{NF}-\kappa \mathrm{B}$ and $\mathrm{p}-\mathrm{I} \kappa \mathrm{B} \alpha / \mathrm{I} \kappa \mathrm{B} \alpha$ proteins; $(\mathrm{b})$ the relative expression of $\mathrm{p}-\mathrm{NF}-\kappa \mathrm{B} / \mathrm{NF}-\kappa \mathrm{B}$ and $\mathrm{p}-\mathrm{I} \kappa \mathrm{B} \alpha / \mathrm{I} \kappa \mathrm{B} \alpha$ proteins was quantified by normalization with group $\mathrm{K}$ and $\beta$-actin according to grayscale; (c) Western blot analysis of p-ERK/ERK, p-JNK/JNK, p-p38/p38 and p-Akt/ Akt proteins; (d) the relative expression of p-ERK/ERK, p-JNK/JNK, p-p38/p38 and p-Akt/Akt proteins was quantified by normalization with group $\mathrm{K}$ and $\beta$-actin according to grayscale. All the values are expressed as mean $\pm \mathrm{SD}(n=3)$. Groups with different letters mean significantly different $(p<0.05)$. K, the Control group; M, $50 \mathrm{ng} / \mathrm{mL}$ RANKL; RL, $50 \mathrm{ng} / \mathrm{mL}$ RANKL and $50 \mu \mathrm{g} / \mathrm{mL}$ of ethanolic extract; RH, $50 \mathrm{ng} / \mathrm{mL}$ RANKL and $100 \mu \mathrm{g} / \mathrm{mL}$ of ethanolic extract; RANKL, receptor activator of nuclear factor- $\mathrm{k}$ ligand; $\mathrm{p}-\mathrm{NF}-\kappa \mathrm{B} / \mathrm{NF}-\mathrm{k}$, phosphorylated-nuclear factor $\kappa \mathrm{B} /$ nuclear factor $\kappa B ; p-I \kappa B \alpha / I \kappa B \alpha$, phosphorylated-inhibitor $\alpha$ of nuclear factor $\kappa B /$ inhibitor $\alpha$ of nuclear factor $\mathrm{\kappa B}$; $\mathrm{p}$-ERK/ERK, phosphorylated-extracellular regulated protein kinases/extracellular regulated protein kinases; p-JNK/JNK, phosphorylated-Jun N-terminal kinase /Jun N-terminal kinase; p-P38/P38, phosphorylated-P38 mitogen-activated protein kinase/P38 mitogen-activated protein kinase; p-Akt/Akt, phosphorylated-protein kinase B/protein kinase B. 

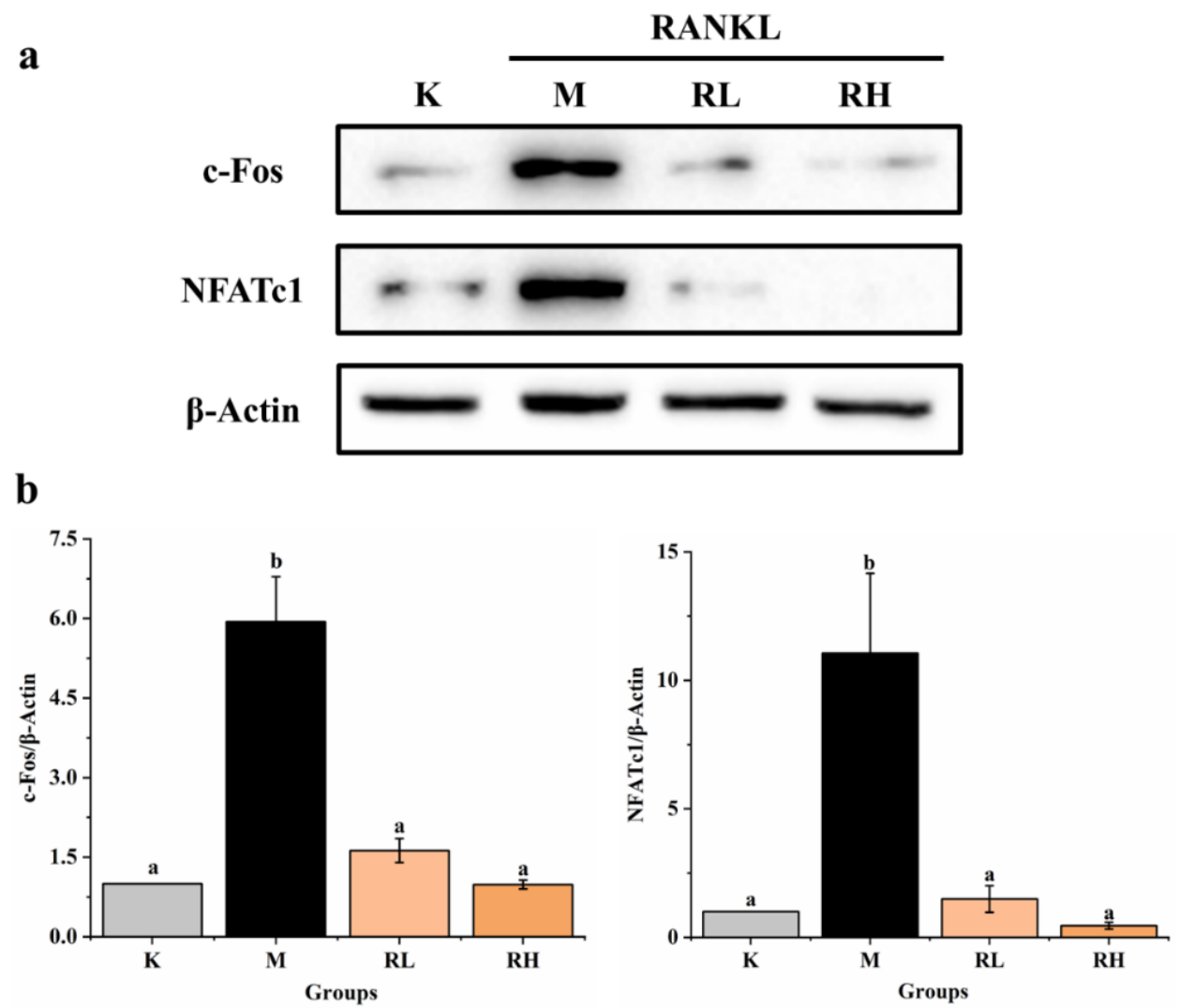

Figure 9. Effects of the ethanolic extract from the R. chinensis fruits on RANKL-induced osteoclastogenesis on c-Fos and NFATc1 proteins in RAW264.7 cells. (a) Western blot analysis of c-Fos and NFATc1 proteins; (b) the relative expression of c-Fos and NFATc1 proteins was quantified by normalization with group $\mathrm{K}$ and $\beta$-actin according to grayscale. All the values are expressed as mean $\pm \operatorname{SD}(n=3)$. Groups with different letters are significantly different $(p<0.05)$. K, the Control group; $\mathrm{M}, 50 \mathrm{ng} / \mathrm{mL}$ RANKL; RL, $50 \mathrm{ng} / \mathrm{mL}$ RANKL and $50 \mu \mathrm{g} / \mathrm{mL}$ of ethanolic extract; RH, $50 \mathrm{ng} / \mathrm{mL}$ RANKL and $100 \mu \mathrm{g} / \mathrm{mL}$ of ethanolic extract; RANKL, receptor activator of nuclear factor- $\mathrm{kB}$ ligand; NFATc1, nuclear factor of activated T-cells cytoplasmic 1.

\section{Discussion}

In this study, 14 components were detected in the ethanolic extract of $R$. chinensis fruits, including 2 kinds of organic acids and 12 kinds of polyphenols. Network pharmacology analysis showed that citric acid, quercetin, myricetin-3-O-galactoside, and quercetin-3-Orhamnoside may be the main potential bioactive components of $R$. chinensis fruits that inhibit osteoclastogenesis, and the main potential targets are AKT1 and MAPK1, and the main potential pathways are PI3K-Akt, AGE-RAGE and MAPKs signaling pathways. Cell experiments and western blotting further verified that the ethanolic extract of the fruits could effectively inhibit the differentiation and formation of osteoclasts, which maybe by regulating the NF- $\mathrm{KB}, \mathrm{Akt}$, and MAPKs signaling pathways, as well as downregulating the expression levels of c-Fos and NFATc1 proteins.

Overexpression of osteoclasts can cause progressive bone loss, which in turn leads to osteoporosis, and may even lead to bone fragility and fractures, which endanger human health [35]. Therefore, it is very important to explore effective natural products to inhibit osteoclastogenesis. Many studies have shown that polyphenols may have an advantageous effect on bone metabolism [36,37]. Foods rich in vegetables, fruits and whole grains were correlated with a lower danger of falls and fractures and an increase in bone density [38]. However, the differentiation of osteoclasts is influenced by multiple signaling pathways, in a complex process [39]. In order to further screen the anti-osteoporosis active components in R. chinensis fruits, as well as the main action pathways and related targets, the method of network pharmacology was used. Network pharmacology can predict active 
ingredients that are highly related to osteoporosis targets. At the same time, network pharmacology can also predict the potential main targets and pathways of these active ingredients. Generally, the network pharmacology results showed that $R$. chinensis fruits may inhibit osteoclastogenesis by inhibiting AKT1 and MAPK1 involved in the PI3K-Akt and MAPKs signaling pathways, respectively (Figures 4 and 6). Citric acid, quercetin, myricetin-3-O-galactoside, and quercetin-3-O-rhamnoside were thought to be the dominant active ingredients for the anti-OP effect of $R$. chinensis fruits (Figure 3). Choi et al. [40], reported that quercetin-3-O-rhamnoside reversed oxidative stress-induced osteoblast dysfunction. The concentration of citric acid in bone is roughly 50-fold higher than that in most soft tissues, suggesting that citric acid plays a major role in the textural properties or features of bone, and serum citric acid level may be a marker of bone loss related diseases; serum citric acid level in OP in animals was significantly lower [13]. In addition, Kim et al. [23], reported that quercetin inhibited osteoclastogenesis, reduced RANKL levels, and decreased RANKL and IL-17-induced differentiation of monocytes to osteoclasts in multiple ways, and could be potentially used as an alternative therapeutic agent in regulating bone destruction and inflammation in rheumatoid arthritis. In addition, those pathways, such as PI3K-Akt, AGE-RAGE, MAPKs, NF-KB and thyroid hormone signaling pathways have been confirmed to be associated with the prevention and/or treatment of OP $[4,41,42]$. Protein NF- $\mathrm{kB}(\mathrm{NF}-\mathrm{kB})$ is known to be associated with several metastatic bone diseases [43], and osteoclast formation [44]. Osteoclast differentiation requires RANK ligands to bind to receptors and subsequently activate multiple intracellular pathways, including AKT/PI3K, MAPK, and NF- $\mathrm{KB}$, which in turn leads to osteoclast formation [45]. Besides the NF- $\mathrm{KB}$ and MAPKs signaling pathways, activation of the PI3K/Akt pathway also plays a key role in the formation of osteoclasts [46]. The PI3K/Akt signaling pathway activated by RANKL has been proved to play a crucial role in regulating osteoclast survival and differentiation [47]. According to the findings of network pharmacological analysis and previous literature, the effect of $R$. chinensis fruits on suppressing RANKL-induced osteoclastogenesis may involve PI3K-Akt, MAPK, and NF-kB signaling pathways.

TRAP is an iron-binding protein that can induce osteoclast differentiation, and high expression levels of TRAP are commonly observed during osteoclast differentiation [48]. It was also found that TRAP could affect the functional activity of osteoclasts by modulating bone matrix absorption and collagen conversion [49]. TRAP is reported to be involved in the migration of osteoclasts to bone adsorption sites, which is the main cause of OP [50]. Therefore, the highly expressed TRAP in osteoclasts is generally used as a phenotypic marker of osteoclasts [51]. Therefore, the ethanolic extract of $R$. chinensis fruits could effectively suppress the differentiation of osteoclasts (Figure 7). Previously, polyphenols have also been reported to reduce TRAP activity in RANKL-induced RAW264.7 cells. For example, Suh et al. [52], showed that xanthohumol significantly inhibited TRAP activity in RANKL-stimulated RAW264.7 cells, and Lee et al. [53], reported that the extract of Ramalina litoralis, rich in phenolic compounds, significantly reduced the mRNA expression of TRAP.

As shown in Figure 8, the ethanolic extract of the fruits inhibited RANKL-stimulated osteoclast formation by inhibiting MAPKs, NF- $\mathrm{KB}$, and Akt signaling pathways, which is consistent with the above prediction results of network pharmacology analysis. MAPKs and NF- $\mathrm{kB}$ signaling pathways play a crucial role in the differentiation and formation of osteoclasts, and the MAPKs cascade is activated by phosphorylating p38, ERK1/2, and JNK $[54,55]$. Those signals interact with NFATc1, the main regulator of osteoclast differentiation, to induce nuclear transfer, and thereby promote osteoclastogenesis [56]. Many previous studies have also reported that many natural products inhibit osteoclastogenesis and prevent $\mathrm{OP}$ by inhibiting MAPKs and NF- $\mathrm{KB}$ signaling pathways. For example, in the study of Hou et al. [57], the expressed levels of NF- $k B$ was significantly reduced in OP rats after being treated with ferulic acid, and ferulic acid showed a good ability to prevent $\mathrm{OP}$ in neonatal rats. Choi et al. [5] reported that Platycodin D inhibited osteoclast differentiation by inhibiting NF-kB and ERK/p38 MAPK signaling pathways. Ang et al. [58], 
also found that naringin could suppress NF- $\mathrm{kB}$ activation and ERK phosphorylation in RANKL-stimulated cells.

In addition, protein c-Fos is intimately related to the occurrence and growth of osteosarcoma, and in the process of osteoclast division, c-Fos is an important adjusting factor of RANKL downstream, which promotes osteoclast shaping mainly by activating the downstream factor NFATc1 [59]. Madhuri et al. [60], also reported that $100 \mu \mathrm{M}$ of ferulic acid markedly inhibited the expressions of c-Fos and NFATc1 genes induced by RANKL and M-CSF. In addition, it is reported that Tatarinan $\mathrm{O}$, a substance obtained from the Acorus tatarinowii Schott roots, could effectively attenuate osteoclastogenesis from RANKL-induced BMMs via lowering the expressed levels of c-Fos and NFATc1 [61]. R. chinensis fruits could effectively inhibit the expression of NFATc1 and c-Fos proteins during the RANKL-induced period. This indicated that the $R$. chinensis fruits have a good inhibitory activity on the differentiation and formation of osteoclasts. In the future, its function in healthcare of diseases related to osteoclast differentiation can be studied to explore its further utilization.

\section{Conclusions}

Results of the current work showed that $R$. chinensis fruits have a preventive effect on the formation of osteoclasts in RAW264.7 cells induced by RANKL, which may involve multiple targets and multiple pathways. Among the 14 identified compounds, citric acid, quercetin, myricetin-3-O-galactoside, and quercetin-3-O-rhamnoside may be the main active components that inhibit osteoclastogenesis. $R$. chinensis fruits significantly inhibited osteoclast formation via adjusting the NF- $\mathrm{kB}, \mathrm{Akt}$, and MAPKs signaling pathways, and by downregulating the expressed levels of c-Fos and NFATc1 proteins. In addition, the main potential targets of $R$. chinensis fruits that inhibit osteoclastogenesis are AKT1 and MAPK1, and the main potential signaling pathways may be AGE-RAGE and PI3K-Akt signaling pathways. This study may supply a basis for further use of $R$. chinensis fruits as a functional food and/or an alternative method for the prevention and improvement of osteoporosis and related diseases.

Author Contributions: Y.Z.: Investigation, Data curation, Writing一original draft. L.Z.: Methodology, Data curation. J.Y.: Writing-reviewing and editing. S.C.: Conceptualization, Funding acquisition, Supervision. All authors have read and agreed to the published version of the manuscript.

Funding: The present work was financially supported by the National Natural Science Foundation of China (Grant No. 31960477) and Yunnan Major Science and Technology Project (202102AE090025).

Institutional Review Board Statement: Not applicable.

Informed Consent Statement: Not applicable.

Data Availability Statement: The data that support the findings of this study are available from the corresponding author upon reasonable request.

Conflicts of Interest: The authors declare no conflict of interest.

\section{References}

1. Wu, Y.; Xie, L.; Wang, M.; Xiong, Q.; Guo, Y.; Liang, Y.; Li, J.; Sheng, R.; Deng, P.; Wang, Y.; et al. Mettl3-mediated m 6 A RNA methylation regulates the fate of bone marrow mesenchymal stem cells and osteoporosis. Nat. Commun. 2018, 9, 4772. [CrossRef]

2. Huang, X.L.; Huang, L.Y.; Cheng, Y.T.; Li, F.; Zhou, Q.; Wu, C.; Shi, Q.H.; Guan, Z.Z.; Liao, J.; Hong, W. Zoledronic acid inhibits osteoclast differentiation and function through the regulation of NF-kB and JNK signalling pathways. Int. J. Mol. Med. 2019, 44, 582-592. [CrossRef] [PubMed]

3. Yin, Z.; Zhu, W.; Wu, Q.; Zhang, Q.; Guo, S.; Liu, T.; Chen, X.; Ouyang, Z. Glycyrrhizic acid suppresses osteoclast differentiation and postmenopausal osteoporosis by modulating the NF-kB, ERK, and JNK signaling pathways. Eur. J. Pharmacol. 2019, 859, 172550. [CrossRef] [PubMed]

4. Jia, L.; Shi, L.; Li, J.; Zeng, Y.; Tang, S.; Liu, W.; Mo, X.; Liu, X. Total flavonoids from celery suppresses RANKL-induced osteoclast differentiation and bone resorption function via attenuating NF-KB and p38 pathways in RAW264. 7 cells. J. Funct. Foods 2020, 69, 103949. [CrossRef] 
5. Choi, J.H.; Han, Y.; Kim, Y.A.; Jin, S.W.; Lee, G.H.; Jeong, H.M.; Lee, H.S.; Chung, Y.C.; Lee, Y.C.; Kim, E.J.; et al. Platycodin D inhibits osteoclastogenesis by repressing the NFATc1 and MAPK signaling pathway. J. Cell. Biochem. 2017, 118, 860-868. [CrossRef] [PubMed]

6. Lademann, F.; Tsourdi, E.; Hofbauer, L.C.; Rauner, M. Thyroid hormone actions and bone remodeling-The role of the wnt signaling pathway. Exp. Clin. Endocrinol. Diabetes 2020, 128, 450-454. [CrossRef]

7. Martyniak, K.; Wei, F.; Ballesteros, A.; Meckmongkol, T.; Calder, A.; Gilbertson, T.; Orlovskaya, N.; Coathup, M.J. Do polyunsaturated fatty acids protect against bone loss in our aging and osteoporotic population? Bone 2020, 143, 115736. [CrossRef] [PubMed]

8. Workman, C.; Blalock, D.V.; Mehler, P.S. Bone density status in a large population of patients with anorexia nervosa. Bone 2020, 131, 115161. [CrossRef] [PubMed]

9. Chen, Q.; Ke, H.; Dai, Z.; Liu, Z. Nanoscale theranostics for physical stimulus-responsive cancer therapies. Biomaterials 2015, 73, 214-230. [CrossRef]

10. Zhu, W.; Yin, Z.; Zhang, Q.; Guo, S.; Shen, Y.; Liu, T.; Wan, L.; Li, S.; Chen, X.; Ouyang, Z.; et al. Proanthocyanidins inhibit osteoclast formation and function by inhibiting the NF- $\mathrm{KB}$ and JNK signaling pathways during osteoporosis treatment. Biochem. Biophys. Res. Commun. 2019, 509, 294-300. [CrossRef]

11. Kim, H.; Lee, Y.D.; Kim, H.J.; Lee, Z.H.; Kim, H.H. SOD2 and Sirt3 control osteoclastogenesis by regulating mitochondrial ROS. J. Bone Miner. Res. 2017, 32, 397-406. [CrossRef] [PubMed]

12. Boyle, W.J.; Simonet, W.S.; Lacey, D.L. Osteoclast differentiation and activation. Nature 2003, 423, 337-342. [CrossRef] [PubMed]

13. Niu, C.; Xiao, F.; Yuan, K.; Hu, X.; Lin, W.; Ma, R.; Zhang, X.; Huang, Z. Nardosinone suppresses RANKL-induced osteoclastogenesis and attenuates lipopolysaccharide-induced alveolar bone resorption. Front. Pharmacol. 2017, 8, 626. [CrossRef]

14. Chawla, S.; Henshaw, R.; Seeger, L.; Choy, E.; Blay, J.Y.; Ferrari, S.; Kroep, J.; Grimer, R.; Reichardt, P.; Rutkowski, P.P.; et al. Safety and efficacy of denosumab for adults and skeletally mature adolescents with giant cell tumour of bone: Interim analysis of an open-label, parallel-group, phase 2 study. Lancet Oncol. 2013, 14, 901-908. [CrossRef]

15. Menshawy, A.; Mattar, O.; Abdulkarim, A.; Kasem, S.; Nasreldin, N.; Menshawy, E.; Mohammed, S.; Maboud, M.A.; Gadelkarim, M.; Ashal, G.G.E.; et al. Denosumab versus bisphosphonates in patients with advanced cancers-related bone metastasis: Systematic review and meta-analysis of randomized controlled trials. Support Care Cancer 2018, 26, 1029-1038. [CrossRef] [PubMed]

16. Bellavia, D.; Caradonna, F.; Dimarco, E.; Costa, V.; Carina, V.; Luca, A.D.; Raimondi, L.; Fini, M.; Gentile, C.; Giavaresi, G. Non-flavonoid polyphenols in osteoporosis: Preclinical evidence. Trends Endocrinol. Metab. 2021, 32, 515-529. [CrossRef]

17. Thomas, A.; South, S.; Vijayagopal, P.; Juma, S. Effect of tart cherry polyphenols on osteoclast differentiation and activity. J. Med. Food 2020, 23, 56-64. [CrossRef] [PubMed]

18. Ghosh, M.; Kim, I.S.; Lee, Y.M.; Hong, S.M.; Lee, T.H.; Lim, J.H.; Debnath, T.; Lim, B.O. The effects of Aronia melanocarpa 'viking' extracts in attenuating RANKL-induced osteoclastic differentiation by inhibiting ROS generation and c-FOS/NFATc1 signaling. Molecules 2018, 23, 615. [CrossRef] [PubMed]

19. Shi, L.; Zheng, L.; Liu, R.; Chang, M.; Huang, J.; Zhao, C.; Jin, Q.; Wang, X. Potential underutilized oil resources from the fruit and seed of Rhus chinensis Mill. Ind. Crops Prod. 2019, 129, 339-344. [CrossRef]

20. Wu, Z.; Ma, Y.; Gong, X.; Zhang, Y.; Zhao, L.; Cheng, G.; Cai, S. Rhus chinensis Mill. fruits prevent high-fat/ethanolic diet-induced alcoholic fatty liver in rats via AMPK/SREBP-1/FAS signaling pathway. J. Funct. Foods 2019, 61, 103498. [CrossRef]

21. Djakpo, O.; Yao, W. Rhus chinensis and Galla Chinensis-Folklore to modern evidence. Phytother. Res. 2010, $24,1739-1747$. [CrossRef]

22. Zhang, C.; Ma, Y.; Zhao, Y.; Hong, Y.; Cai, S.; Pang, M. Phenolic composition, antioxidant and pancreatic lipase inhibitory activities of Chinese sumac (Rhus chinensis Mill.) fruits extracted by different solvents and interaction between myricetin-3-O-rhamnoside and quercetin-3-O-rhamnoside. Int. J. Food Sci. Technol. 2018, 53, 1045-1053. [CrossRef]

23. Kim, H.-R.; Kim, B.-M.; Won, J.-Y.; Lee, K.-A.; Ko, H.M.; Kang, Y.S.; Lee, S.-H.; Kim, K.-W. Quercetin, a plant polyphenol, has potential for the prevention of bone destruction in rheumatoid arthritis. J. Med. Food 2019, 22, 152-161. [CrossRef] [PubMed]

24. Guo, C.; Hou, G.-Q.; Li, X.-D.; Xia, X.; Liu, D.-X.; Huang, D.-Y.; Du, S.-X. Quercetin triggers apoptosis of lipopolysaccharide (LPS)-induced osteoclasts and inhibits bone resorption in RAW264. 7 cells. Cell. Physiol. Biochem. 2012, 30, 123-136. [CrossRef] [PubMed]

25. Sun, D.; Huang, S.; Cai, S.; Cao, J.; Han, P. Digestion property and synergistic effect on biological activity of purple rice (Oryza sativa L.) anthocyanins subjected to a simulated gastrointestinal digestion in vitro. Food Res. Int. 2015, 78, 114-123. [CrossRef] [PubMed]

26. Yang, Y.; Li, Y.; Wang, J.; Sun, K.; Tao, W.; Wang, Z.; Xiao, W.; Pan, Y.; Zhang, S.; Wang, Y. Systematic investigation of Ginkgo biloba leaves for treating cardio-cerebrovascular diseases in an animal model. ACS Chem. Biol. 2017, 12, 1363-1372. [CrossRef]

27. Gfeller, D.; Grosdidier, A.; Wirth, M.; Daina, A.; Michielin, O.; Zoete, V. SwissTargetPrediction: A web server for target prediction of bioactive small molecules. Nucleic Acids Res. 2014, 42, W32-W38. [CrossRef]

28. Liu, X.; Ouyang, S.; Yu, B.; Liu, Y.; Huang, K.; Gong, J.; Zheng, S.; Li, Z.; Li, H.; Jiang, H. PharmMapper server: A web server for potential drug target identification using pharmacophore mapping approach. Nucleic Acids Res. 2010, 38, W609-W614. [CrossRef] [PubMed] 
29. Wishart, D.S.; Feunang, Y.D.; Guo, A.C.; Lo, E.J.; Marcu, A.; Grant, J.R.; Sajed, T.; Johnson, D.; Li, C.; Sayeeda, Z.; et al. DrugBank 5.0: A major update to the DrugBank database for 2018. Nucleic Acids Res. 2018, 46, D1074-D1082. [CrossRef]

30. Stelzer, G.; Rosen, N.; Plaschkes, I.; Zimmerman, S.; Twik, M.; Fishilevich, S.; Stein, T.I.; Nudel, R.; Lieder, I.; Mazor, Y.; et al. The GeneCards suite: From gene data mining to disease genome sequence analyses. Curr. Protoc. Bioinform. 2016, 54, 1-30. [CrossRef]

31. Wang, Y.; Zhang, S.; Li, F.; Zhou, Y.; Zhang, Y.; Wang, Z.; Zhang, R.; Zhu, J.; Ren, Y.; Tan, Y.; et al. Therapeutic target database 2020: Enriched resource for facilitating research and early development of targeted therapeutics. Nucleic Acids Res. 2020, 48, D1031-D1041. [CrossRef] [PubMed]

32. UniProt Consortium. UniProt: A hub for protein information. Nucleic Acids Res. 2015, 43, D204-D212. [CrossRef]

33. Abu-Reidah, I.M.; Ali-Shtayeh, M.S.; Jamous, R.M. Hplc-dad/qtof-ms screening of bioactive components from Rhus coriaria L. fruits. Food Chem. 2015, 166, 179-191. [CrossRef]

34. Kumar, S.; Chandra, P.; Singh, A. Rapid qualitative and quantitative analysis of bioactive compounds from Phyllanthus amarus using LC/MS/MS techniques. Ind. Crops Prod. 2015, 69, 143-152. [CrossRef]

35. Langsetmo, L.; Hanley, D.A.; Prior, J.C.; Barr, S.I.; Anastassiades, T.; Towheed, T.; Goltzman, D.; Morin, S.; Poliquin, S.; Kreiger, N. Dietary patterns and incident low-trauma fractures in postmenopausal women and men aged $\geq 50 \mathrm{y}$ : A population-based cohort study. Am. J. Clin. Nutr. 2011, 93, 192-199. [CrossRef]

36. Blangy, A.; Bompard, G.; Guerit, D.; Marie, P.; Maurin, J.; Morel, A.; Vives, V. The osteoclast cytoskeleton-Current understanding and therapeutic perspectives for osteoporosis. J. Cell Sci. 2020, 133, jcs244798. [CrossRef]

37. Đudarić, L.; Fužinac-Smojver, A.; Muhvić, D.; Giacometti, J. The role of polyphenols on bone metabolism in osteoporosis. Food Res. Int. 2015, 77, 290-298. [CrossRef]

38. Brito, C.; Stavroullakis, A.T.; Ferreira, A.C.; Li, K.; Oliveira, T.; Nogueira-Filho, G.; Prakki, A. Extract of acai-berry inhibits osteoclast differentiation and activity. Arch. Oral Biol. 2016, 68, 29-34. [CrossRef] [PubMed]

39. Blair, H.C.; Robinson, L.J.; Zaidi, M. Osteoclast signalling pathways. Biochem. Biophys. Res. Commun. 2005, 328, 728-738. [CrossRef] [PubMed]

40. Choi, E.M. Protective effect of quercitrin against hydrogen peroxide-induced dysfunction in osteoblastic MC3T3-E1 cells. Exp . Toxicol. Pathol. 2012, 64, 211-216. [CrossRef]

41. Yoon, B.H.; Lee, Y.; Oh, H.J.; Kim, S.H.; Lee, Y.K. Influence of thyroid-stimulating hormone suppression therapy on bone mineral density in patients with differentiated thyroid cancer: A meta-analysis. J. Bone Metab. 2019, 26, 51-60. [CrossRef] [PubMed]

42. Li, Z.; Zhang, W.; Huang, Y. MiRNA-133a is involved in the regulation of postmenopausal osteoporosis through promoting osteoclast differentiation. Acta Biochim. Biophys. Sin. 2018, 50, 273-280. [CrossRef] [PubMed]

43. Vassiliou, V. Management of metastatic bone disease in the elderly with bisphosphonates and receptor activator of NF-kB ligand inhibitors: Effectiveness and safety. Clin. Oncol. 2013, 25, 290-297. [CrossRef] [PubMed]

44. Wu, Q.; Li, S.; Li, X.; Sui, Y.; Yang, Y.; Dong, L.; Xie, B.; Sun, Z. Inhibition of advanced glycation endproduct formation by lotus seedpod oligomeric procyanidins through RAGE-MAPK signaling and NF-kB activation in high-fat-diet rats. J. Agric. Food Chem. 2015, 63, 6989-6998. [CrossRef] [PubMed]

45. Li, D.Z.; Zhang, Q.X.; Dong, X.X.; Li, H.D.; Ma, X. Treatment with hydrogen molecules prevents RANKL-induced osteoclast differentiation associated with inhibition of ROS formation and inactivation of MAPK, AKT and NF-kappa B pathways in murine RAW264. 7 cells. J. Bone Miner. Metab. 2014, 32, 494-504. [CrossRef] [PubMed]

46. Moon, J.B.; Kim, J.H.; Kim, K.; Youn, B.U.; Ko, A.; Lee, S.Y.; Kim, N. Akt induces osteoclast differentiation through regulating the GSK3 $\beta$ /NFATc1 signaling cascade. J. Immunol. 2012, 188, 163-169. [CrossRef]

47. Mandal, C.C.; Ghosh Choudhury, G.; Ghosh-Choudhury, N. Phosphatidylinositol 3 kinase/Akt signal relay cooperates with smad in bone morphogenetic protein-2-induced colony stimulating factor-1 (CSF-1) expression and osteoclast differentiation. Endocrinology 2009, 150, 4989-4998. [CrossRef] [PubMed]

48. Sapkota, M.; Li, L.; Choi, H.; Gerwick, W.H.; Soh, Y. Bromo-honaucin A inhibits osteoclastogenic differentiation in RAW 264.7 cells via Akt and ERK signaling pathways. Eur. J. Pharmacol. 2015, 769, 100-109. [CrossRef] [PubMed]

49. Choi, J.; Choi, S.Y.; Lee, S.Y.; Lee, J.Y.; Kim, H.S.; Lee, S.Y.; Lee, N.K. Caffeine enhances osteoclast differentiation and maturation through p38 MAP kinase/Mitf and DC-STAMP/CtsK and TRAP pathway. Cell. Signal. 2013, 25, 1222-1227. [CrossRef] [PubMed]

50. Sheu, T.J.; Schwarz, E.M.; Martinez, D.A.; O'Keefe, R.J.; Rosier, R.N.; Zuscik, M.J.; Puzas, J.E. A phage display technique identifies a novel regulator of cell differentiation. J. Biol. Chem. 2003, 278, 438-443. [CrossRef] [PubMed]

51. Yan, X.T.; Lee, S.H.; Li, W.; Jang, H.D.; Kim, Y.H. Terpenes and sterols from the fruits of Prunus mume and their inhibitory effects on osteoclast differentiation by suppressing tartrate-resistant acid phosphatase activity. Arch. Pharmacal Res. 2015, 38, 186-192. [CrossRef] [PubMed]

52. Suh, K.S.; Rhee, S.Y.; Kim, Y.S.; Lee, Y.S.; Choi, E.M. Xanthohumol modulates the expression of osteoclast-specific genes during osteoclastogenesis in RAW264. 7 cells. Food Chem. Toxicol. 2013, 62, 99-106. [CrossRef] [PubMed]

53. Lee, Y.; Jeong, M.H.; Kim, K.J.; Baek, S.H.; Hur, J.S.; Son, Y.J. The extract of Ramalina litoralis inhibits osteoclast differentiation. Biotechnol. Bioprocess. Eng. 2018, 23, 634-640. [CrossRef]

54. An, Y.; Zhang, H.; Wang, C.; Jiao, F.; Xu, H.; Wang, X.; Luan, W.; Ma, F.; Ni, L.; Tang, X.; et al. Activation of ROS/MAPKs/NFKB/NLRP3 and inhibition of efferocytosis in osteoclast-mediated diabetic osteoporosis. FASEB J. 2019, 33, 12515-12527. [CrossRef] [PubMed] 
55. Brown, K.D.; Claudio, E.; Siebenlist, U. The roles of the classical and alternative nuclear factor-kappaB pathways: Potential implications for autoimmunity and rheumatoid arthritis. Arthritis Res. Ther. 2008, 10, 212. [CrossRef] [PubMed]

56. Takayanagi, H. The role of NFAT in osteoclast formation. Ann. N. Y. Acad. Sci. 2007, 1116, 227-237. [CrossRef]

57. Hou, T.; Zhang, L.; Yang, X. Ferulic acid, a natural polyphenol, protects against osteoporosis by activating SIRT1 and NF-KB in neonatal rats with glucocorticoid-induced osteoporosis. Biomed. Pharmacother. 2019, 120, 109205. [CrossRef] [PubMed]

58. Ang, E.S.; Yang, X.; Chen, H.; Liu, Q.; Zheng, M.H.; Xu, J. Naringin abrogates osteoclastogenesis and bone resorption via the inhibition of RANKL-induced NF- $\mathrm{kB}$ and ERK activation. FEBS Lett. 2011, 585, 2755-2762. [CrossRef]

59. Jeong, B.C.; Kim, J.H.; Kim, K.; Kim, I.; Seong, S.; Kim, N. ATF3 modulates calcium signaling in osteoclast differentiation and activity by associating with c-Fos and NFATc1 proteins. Bone 2017, 95, 33-40. [CrossRef] [PubMed]

60. Doss, H.M.; Samarpita, S.; Ganesan, R.; Rasool, M. Ferulic acid, a dietary polyphenol suppresses osteoclast differentiation and bone erosion via the inhibition of RANKL dependent NF-кB signalling pathway. Life Sci. 2018, 207, 284-295. [CrossRef]

61. Xu, X.; Liu, N.; Wang, Y.; Pan, L.C.; Wu, D.; Peng, Q.; Zhang, M.; Wang, H.B.; Sun, W.C. Tatarinan O, a lignin-like compound from the roots of Acorus tatarinowii Schott inhibits osteoclast differentiation through suppressing the expression of c-Fos and NFATc1. Int. Immunopharmacol. 2016, 34, 212-219. [CrossRef] 